\title{
Quality of the equipment used in the mining rescue activity in Romania and the nature of their specific requests
}

\author{
Cristian Ilioni ${ }^{*}$ \\ ${ }^{1}$ University of Petroșani, 20 Universității, Petroșani, Romania
}

\begin{abstract}
Occupational safety and health is increasingly considered to be a distinct scientific discipline, with a well-defined place in the labor sciences system. The evolution of research in recent years at European and international level has highlighted an increasing interpenetration of occupational safety and health with other scientific disciplines circumscribed or related to the field of industrial engineering, such as medicine and occupational hygiene, ergonomics, sociology, mathematics, computer science etc. In national legislation, the intervention and rescue activity in toxic / explosive / flammable environments has so far proved to be generally appropriate both in terms of prevention and in terms of limiting the effects of technological damage of lesser or greater magnitude. The theoretical and instrumental aspects presented in the paper have a wide applicability, being intended for all rescue stations, regardless of the branch of activity, as well as for specialists in the field of occupational safety and health. Understanding the relationship between the environment, equipment and rescue station personnel and ho-w these three components interact is fundamental to achieving increased efficiency in rescue work.
\end{abstract}

\section{Introduction}

The increased importance of evaluating the way of adapting to the specifics of jobs in the perspective of developing prophylactic actions to combat risk factors and reduce their impact, requires, above all, knowledge, but also the development and development of methods and techniques of work analysis in in order to establish the necessary measures for the efficiency of the optimal mutual adaptation between the executor and the professional task and the physical and psychosocial ambiance of the activity. The ergonomic problems that arise must be known, because dysfunctions, incompatibilities in the human-workenvironment system, together with the intensity of demands and subjective discomfort factors, can generate accentuated states of fatigue and stress, which somatize in morphofunctional disorders of the body with direct repercussions. on the efficiency in activity.

*Corresponding author: c_ilioni@yahoo.com 
It is necessary to emphasize concerns in this area, as well as information on the status of the problem in other countries. From the latter point of view, two distinct orientations must be emphasized: in some Western European countries - such as France, England, Germany in particular - labor analysis is associated and indispensable with ergonomic actions, while in the U.S.A. "Job analysis" is the foundation of the organizational system of human resources management, from which derive its main components (recruitment, selection, training, professional development and performance evaluation.

\section{The importance of rescue activity in units underground activity}

Activity under special conditions [1], created as a result of underground damage and endangering personnel or material goods, where due to exceeding the concentrations of toxic or asphyxiating gases, vapors and dusts established by norms, which require the use of insulating devices for respiratory protection, are ensured through rescue stations.

Also, during these damages, when there is a danger of toxic or asphyxiating gases, vapors and dusts at the interception of old works, massive voids, at the control and research of some areas with uncertain atmosphere [1], as well as in other situations established and approved by the technical leader of the unit, until a breathable atmosphere is achieved [1], the works will be performed with the personnel of the rescue stations. The number of rescuers from a mining unit represents at least $2 \%$ of the most populated exchange, but not less than 10 rescuers.

The rescue activity is organized through rescue stations at the mining units or central rescue stations. The spaces allocated to the rescue station must ensure:

- adequate conditions for theoretical training of rescue station personnel;

- storage of isolating devices, control devices, resuscitation devices;

- storage of rescue materials and spare parts;

- storage of transportable pressure vessels used in respiratory protection devices, in compliance with the applicable ISCIR technical prescriptions.

- The minimum endowment of the rescue stations consists of [2]:

- one insulating appliance in suitable working order for each rescuer and one spare insulating appliance for every 5 insulating appliances;

- one universal control device for every 10 insulating devices, but not less than two;

- one resuscitation device for every 10 isolating devices, but not less than two;

- for each insulating device, two cylinders of compressed oxygen (compressed air), like a reserve, loaded;

- one bag of sanitary kit for each team; one safety belt with rope and hooks for each 5 insulating devices;

- one stretcher for every 5 insulating devices.

- The conditions for staffing at rescue stations are as follows [3]:

- be between 20-50 years old for operational staff and up to 55 years old for control and coordination staff;

- to be trained and authorized by INCD INSEMEX Petroşani; be declared medically and psychologically fit to perform the activities of intervention and rescue in toxic / explosive / flammable environments.

The control and coordination [1] of the rescue activity during the interventions is performed by the personnel with technical training. 


\section{Evaluation of job-specific applications}

Professional activities, no matter how varied, involve a neuromuscular participation (defined as physical work) and a neuropsychic participation (defined as intellectual work). Although in some conceptions there is talk of a certain annihilation of the division in the two activities, the appreciation that there is a marked differentiation between the predominantly physical work and the predominantly intellectual one continues to predominate. In both forms of activity, the intervention of both the psychoneurosensory system and the musculoskeletal system cannot cancel the differences between physical and intellectual work in terms of physiology.

Physical work is a complex process of the body, in which the mobilization of the musculoskeletal system is the way to complete, for this purpose being involved the cardiovascular, respiratory, nervous system and internal organs in a unitary whole.

From the mentioned statement, the analysis of the muscular labor is required. From the point of view of physical effort, the main mechanical properties of muscle are elasticity and contractility, which are due to muscle activity. The onset of muscle contraction depends on a motor neuron that transmits nerve influx through the neuro-muscular plate $[4,5]$.

Muscle contraction can occur due to complex chemical phenomena that occur in the muscle. First of all, it should be noted that muscle is made up of protein, a quantity of lipids, mineral salts and chemicals with an important role in muscle contraction. The participation of the cardiovascular and respiratory systems is very important in the development of the muscular and respiratory system in order to ensure the needs of oxygen and glucose. Muscle labor takes place in three phases: onset, condition and recovery (Figure 1).

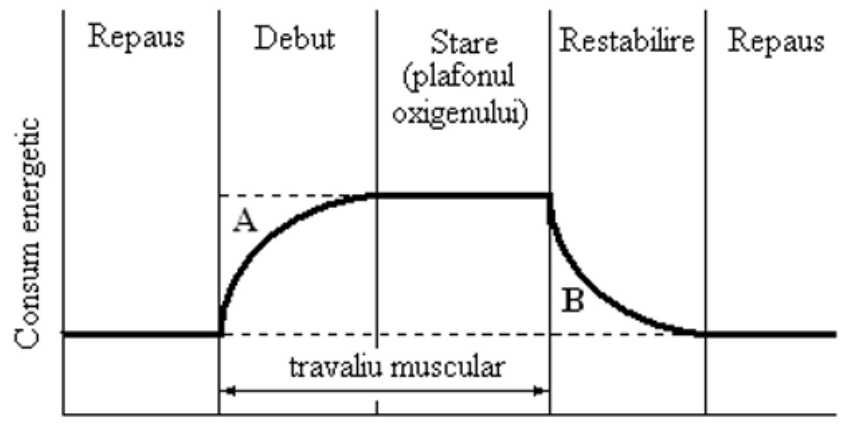

A - datoria de oxigen; B - plata datoriei de oxigen

Fig.1. Energy consumption in muscle labor.

The onset period takes place in conditions of "oxygen duty", the cardiovascular and respiratory system, not being able to adapt very quickly to exercise, does not provide, in this phase especially, the necessary oxygen. During the condition, a proper blood supply of the active muscle is performed. In this phase a dynamic balance is achieved, the condition of which is that the effort is not so great that the possible oxygen supply to be achieved through the cardiovascular and respiratory capacity is exceeded by the required amount of oxygen. The maximum limit of possible oxygen supply per unit time defines the "oxygen ceiling", whose value differs from person to person depending on the functional state of the cardiovascular and respiratory system.

In the recovery stage, which begins with the cessation of muscle contraction, the continued consumption of oxygen at the muscular level continues for the "payment of the oxygen debt", both for the one accumulated in the beginning stage and for the one added by 
the possible intense effort. need oxygen over the ceiling. During this period, the cardiovascular and respiratory systems continue an increased activity, returning to normal depending on the full insurance of the payment of the "oxygen debt".

The measurement or estimation of energy consumption is done by the following methods:

- measuring the calories released by the body by placing it in a calorimeter;

- researching the exact composition of the absorbed foods and the total evaluation by knowing the caloric power of each of them;

- measuring the volume of oxygen consumed and that of carbon dioxide removed.

Under conditions of muscle rest, the body uses a certain amount of energy for its activities - which is the so-called basal metabolism. During exercise the basal metabolism can be exceeded up to 10 times. In order to achieve compatibility between the requirements of the profession and the individual's ability to perform, a large number of batteries of psychological tests are used. According to the objectives pursued, the tests are intended to measure intelligence or mental level, skills, behavior, motor skills, sensory-perceptual qualities etc.

- evaluation of the influence of psychological constraint on physiological indicators.

The effects of workload and professional discomfort can be detected with specific indicators and methods at different levels: from simple sensory changes to integrative behavioral disorders and complex aspects, which involve the dynamics of human personality.

The lack of specificity of some objective indicators often leads to similar evolutions to different triggering events. Under these conditions, the use of subjective indicators becomes very important. The main indicators refer to accusations, embarrassment, complaints, feelings of lethargy, asthenia, saturation. Opposite phenomena of hyperactivation, tension can also occur, which become chronic not only during the request, but also after its cessation. At the same time, there are frequent motivational or volitional collapses, as well as memory disorders and difficulty concentrating. At the level of personality and behavior, there may be changes in emotional balance and stability, as well as the accentuation of neuropathic or asthenic tendencies and disorders. This complex symptomatic picture, defining for the characterization of the general state of health of the individual or at the level of socio-professional group, covers several fields: psychosensory, neurovegetative, osteoarticular, psychoaffective, immunological etc.

\section{Equipment used in the mining rescue activity in Romania}

\subsection{Insulating breathing apparatus type MEDI 494}

It was manufactured in the 60's by the company MEDIZINTECHNIK [3] from Leipzig Germany and today it is still equipped with mining rescue stations, being sometimes even preferred by rescuers in the actions of liquidation of damages due to the feeling of security that gives them.

The device (Figure 2) weighs approximately $18 \mathrm{~kg}$, has a duration of use between $2 \div 4$ hours, depending on the oxygen reserve and the type of filter cartridge used. The oxygen cylinder is made of alloy steel, has a capacity of 2 liters and is charged at 150 or $200 \mathrm{~atm}$., Storing 300 or 400 liters of oxygen. 

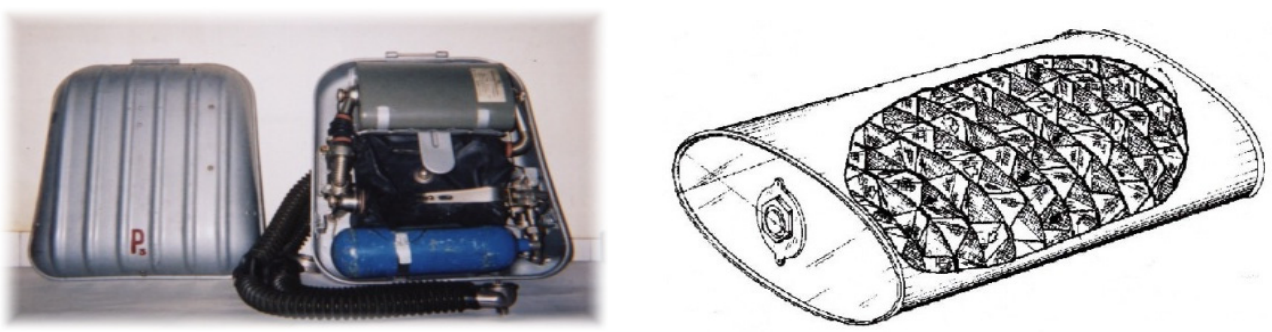

Fig. 2. Respiratory protection device Medi 494 and the filter cartridge.

The filter cartridges used are produced by Romcarbon Buzău (Figure 2), contain sodium hydroxide $(\mathrm{NaOH})$ inside and have a different duration of use, depending on the dimensions, as follows:

- $1 \mathrm{~h}: 7 \times 14 \times 21 \mathrm{~cm}$ and she wear approx. $1,7 \mathrm{~kg}$

- $2 \mathrm{~h}: 9 \times 18 \times 24 \mathrm{~cm}$ and she wear approx.2,5 kg

- $4 \mathrm{~h}$ : $9 \times 18 \times 24 \mathrm{~cm}$ and she wear approx. $3,2 \mathrm{~kg}$.

This device works with negative pressure and is equipped with a valve that can stop the access of oxygen to the finimetric pipe in case it deteriorates, oxygen losses occur.

\subsection{Insulating breathing apparatus type MEDI 17128}

It is the type of device (Figure 3) Most used in the intervention and rescue activity in the extractive industry in our country.

The device was produced by MEDIZINTECHNIC from the former R.D.G., being manufactured in the '70s and' 80 s, respectively. Unlike the older types, it weighs less, about $14 \mathrm{~kg}$, is small in size, making it easier for rescuers to pass the device through narrow spaces, and is equipped with self-sealing gaskets that allow all connections to be tightened by hand. The duration of use of this device is 2 - 4 hours, using 2 liter oxygen cylinders and 2 or 4 hour filter cartridges.

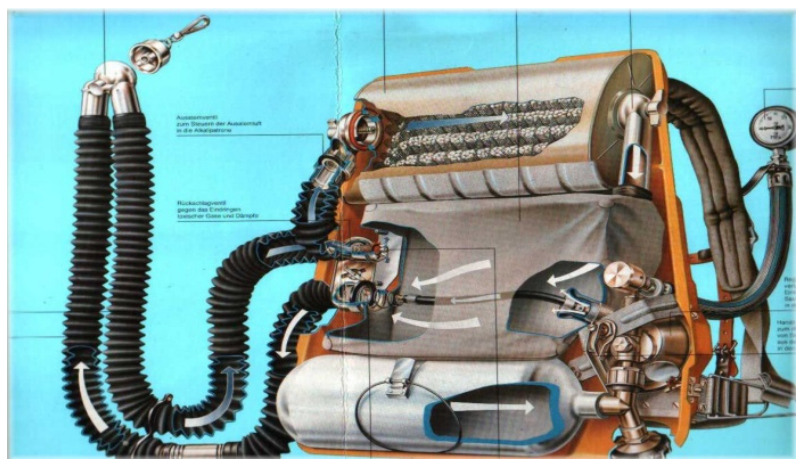

Fig. 3. Respiratory protection device Medi 17128.

This device is not equipped with a lifeguard warning system, at a certain pressure, being equipped only with a safety valve that stops the access of oxygen to the finimeter and warns audibly in case the finimetric pipe deteriorates and oxygen losses occur. The overflow valve, through which the surplus air resulting in the appliance circuit from the amount of oxygen supplied from the reducer is released to the outside, opens to the value of $20-40$ $\mathrm{mm} \mathrm{H}_{2} \mathrm{O}$ column, and the fact that it is placed on the side of the breathing bag, causes that, 
when the lid of the device is not tightly closed, it opens at higher pressure values, requiring the rescuer in the expiration phase, an additional effort. There is a pre-fill valve on the back of the device, which is operated only before starting work with the isolating device to freshen the air in the breathing bag. In this type of apparatus, the value of the fixed dosage increases in proportion to the reduction of the oxygen pressure in the cylinder.

\subsection{Respiratory protection device type MEDI 16215}

It is a device that works on the basis of open circuit compressed air, the exhaled air being released through the sealing valve of the sealing mask directly into the atmosphere, having a duration of use of 50 minutes. The device (Figure 4) weighs almost $15 \mathrm{~kg}$, is equipped with 2 bottles with a capacity of 4 liters each and is loaded at $200 \mathrm{~atm}$. with the help of a high-pressure compressor, thus storing 1600 liters of air.

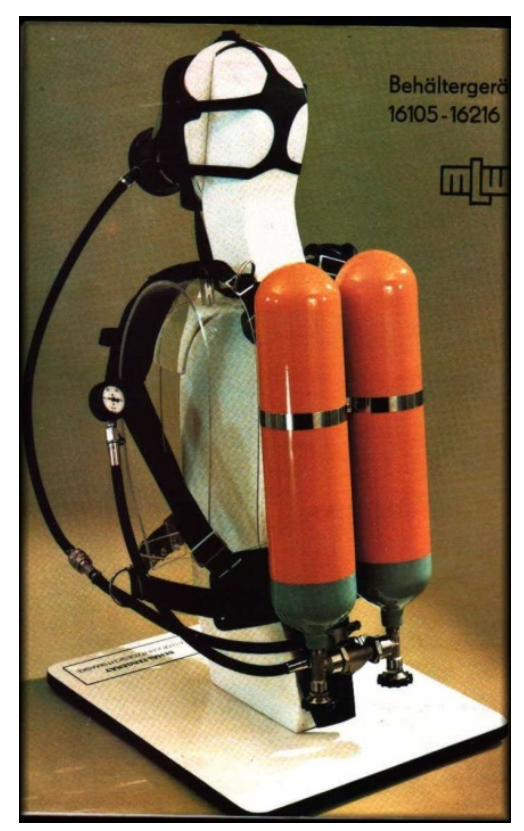

Fig. 4. Respiratory protection device Medi 16216.

The devices can be used without restrictions at an ambient temperature between -300C and $+700 \mathrm{C}$ and a relative humidity of $90 \%$ at a temperature of $+400 \mathrm{C}$. The pulmonary machine is provided with a tilting valve which in the inspiration phase, at a depression between $-15--35 \mathrm{~mm} \mathrm{H}_{2} \mathrm{O}$ column, opens providing the mask with the air necessary for breathing, and when the depression in the mask disappears, the valve automatically closes the air access. The compressed air is supplied "on request" during the inspiration phase, and the exhaled air is released directly into the atmosphere through the sealing valve of the sealing mask. The supply pipe consists of 2 segments joined by a metal coupling, where 2 terminal ends can be connected with pulmonary automatic (additional sealed hose having a length of 2 meters); thus, the rescuer can evacuate with him a person caught in the area with toxic environment. 


\subsection{DRAGER BG-4 type respiratory}

The DRAGER BG4 device (figure 5) is made by the DRAGER company in three variants EP, I8, and FEP that have common constructive and functional parameters, operate on the basis of compressed oxygen as devices with positive pressure and operating time of 4 hours. The device has the dimensions of 59 x $45 \times 18 \mathrm{~cm}$. and weighs $14.8 \mathrm{~kg}$ when fully equipped, including the sealing mask and $1.2 \mathrm{~kg}$ of ice in the cooler. The fixed dosage of the device is between $1.5-1.9$ liters of oxygen / minute, and through the through-valve it can ensure a flow higher than 50 liters of oxygen / minute, through the manual addition valve it can ensure a flow of up to 80 liters of oxygen / minute.

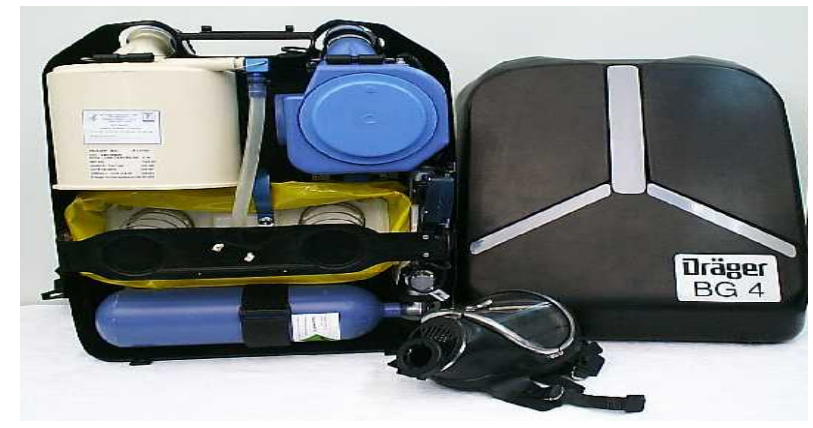

Fig. 5. Drager BG4 respiratory.

The exhaled air passes through the mask through the exhalation valve, exhalation hose and enters the container with absorbent substance where $\mathrm{CO} 2$ is retained from the exhaled air, then passes into the breathing bag with a capacity of 5.5 liters. Two springs maintain the positive pressure in the device circuit, so the resistance to inspiration (for a respiratory rate of 25 breaths and an inspired volume of 2 liters minutes) is greater than $10 \mathrm{~mm}$. $\mathrm{H} 2 \mathrm{O}$ column, and on expiration should be less than $7 \mathrm{~mm}$. H2O column. The refillable filter cartridge contains Dragersorb, a substance that will be replaced after each use of the appliance. The overflow valve is operated according to the volume of air in the breathing bag and must open between 4 and $7 \mathrm{~mm}$. H2O column, evacuating into the atmosphere the breathed air it takes from its entry into the filter cartridge.

The liquid crystal display shows us the oxygen pressure in the cylinder makes a test of the tightness of the device in approx. 10 seconds, check its dosage and the tightness of the high pressure circuit, and when in the oxygen cylinder it has dropped to $55 \mathrm{~atm}$, it warns optically and acoustically by emitting a sound for 30 seconds, and at a pressure of $10 \mathrm{~atm}$. the sound becomes continuous. The device is used with the Panorama Nova sealing mask, which is equipped with an internal viewfinder wiper, thus ensuring visibility when working with the device.

\subsection{DRAGER PA 90 respiratory}

It is produced by DRAGER, being a device that works on the basis of compressed air, with positive pressure [3]. The device (Figure 6) consists of a back support made of carbon fiber, highly thermally and mechanically resistant material, textile harness made of burn-resistant materials, and a compact pressure reducer that reduces the pressure to $7.5 \mathrm{~atm}$. being provided with a safety valve that opens at $13 \mathrm{~atm}$. 


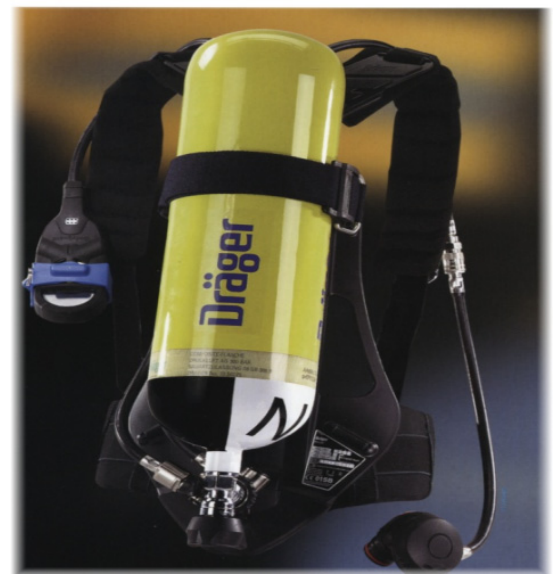

Fig. 6. Drager PA 90 respiratory.

The dimensions of the device are $62 \times 32 \times 15 \mathrm{~cm}$, it weighs $3 \mathrm{~kg}$ and one or two cylindrical cylinders with capacities between 4 and 12 liters can be attached to it, having the loading pressure between $200 \div 300$ atm made of steel or carbon fiber composite materials . For mounting two cylinders to the gearbox, the device comes with an additional Y-shaped part that allows this. The weight of the device and the duration of operation depend on the material from which they are made, the number and capacity of the bottles (for a 6 liter steel bottle, the weight of the device is $12 \mathrm{Kg}$, and with a composite bottle its weight is $7 \mathrm{Kg}$ The finimeter of the appliance is fixed with an elastic element, the dial being marked phosphorescent, and on its pipe is mounted the audible warning system, which comes into operation at a pressure of $55 \pm 5$ atmospheres. and ensures a positive pressure inside the sealing mask of maximum $50 \mathrm{~mm} \mathrm{H} 2 \mathrm{O}$ column, being provided with a button to block the air flow when the appliance is put into operation but we do not use it. The system unlocks automatically in case which creates depression inside the mask.

\section{Usefulness and purpose of the analysis}

Activity analysis is a first step and a sine qua non condition in any field of work psychology or philosophy. In essence, it consists in highlighting - through a series of specific methods and techniques - all the variables that condition the work of the human operator, the two components, work and the individual, being in a systemic interconditioning relationship. At the basis of this approach is, in the last resort, a difficult process of gathering information, the development of which is in sequences.

It should be emphasized, from the beginning, that the analysis of work is not done as an end in itself, but pursues concrete objectives both at the individual level (increasing professional satisfaction) and at the level of the entire organization (increasing production efficiency, ensuring socio-technical reliability). .

Analytical knowledge of work processes is indispensable in the perspective of developing prophylactic actions. In any work process we are dealing with two realities of a different nature: on the one hand the prescribed tasks and operations, and on the other hand the behavior in the real production activity. Because of this, the activity can be described either in engineering terms, using as descriptors the technical standards and operating instructions, or in psycho-medical terms - skills, demands, etc. It should be noted that only the investigation of working conditions and the content of the activity does not indicate the degree of stress or psycho-physical attributes necessary to perform the activity. At the same 
time, the simple evaluation of the working conditions cannot result directly from the conduct with its reasons, nor from the possible neuropsychic request.

When the analysis aims to establish an ergonomic diagnosis, its specificity becomes the adaptation of the work to the human capacities, ie obtaining an adequate balance between the physical or mental load and the performance capacities of the performers.

\section{Conclusions}

So here are the factors that lead to the idea that the rescue activity must be treated with more and more attention and consideration and that no effort is too much when considering various actions to improve it. The traditional partner in the endowment with rescue equipment for mining in our country, for over 30 years, was the company MEDIZINTECHNIC from the former GDR. Since it merged in 1990 with the company DRÄGER, from which time it stopped production, the endowment of rescue stations has remained at the level of the '90s, since no import of equipment was made, and today it has become imperative. it is necessary to purchase new, modern and reliable equipment.

\section{References}

1. G.A.Găman, , ş.a., Reevaluarea şi reorganizarea activităţii de salvare în medii toxice şi / sau explozive în condiţii de creştere a eficienţei şi a gradului de operativitate în intervenţii, Studiu INCD INSEMEX (2001)

2. G.A.Găman, , ş.a., Principii, tehnici şi proceduri de intervenţie şi salvare în medii toxice / explozive / inflamabile, (Editura Insemex, Petroşani, 2007)

3. R. Moraru, R., Securitate şi sănătate în muncă. Tratat universitar, (Editura Focus, Petroşani, 2013)

4. R. Nielsen R., J.P. Meyer, Evaluation of metabolism from heart rate in industrial work, (Ergonomics, 1987) 